\title{
Management of newborns exposed to mothers with confirmed or suspected COVID-19
}

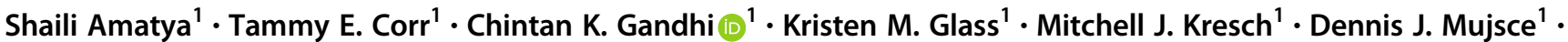 \\ Christiana N. Oji-Mmuo ${ }^{1}$ - Sara J. Mola ${ }^{1}$ - Yuanyi L. Murray ${ }^{1} \cdot$ Timothy W. Palmer $^{1} \cdot$ Meenakshi Singh $^{1}$. \\ Ashley Fricchione ${ }^{2}$. Jill Arnold ${ }^{2} \cdot$ Danielle Prentice $^{3} \cdot$ Colin R. Bridgeman $^{4} \cdot$ Brandon M. Smith $^{4} \cdot$ Patrick J. Gavigan $^{5}$. \\ Jessica E. Ericson $\mathbb{1}^{5}$ - Jennifer R. Miller ${ }^{6}$ - Jaimey M. Pauli ${ }^{3}$ - Duane C. Williams ${ }^{7}$. George D. McSherry ${ }^{5}$. \\ Richard S. Legro ${ }^{3} \cdot$ Sarah M. Iriana ${ }^{6} \cdot$ Jeffrey R. Kaiser $\mathbb{B}^{1,3}$
}

Received: 12 April 2020 / Revised: 5 May 2020 / Accepted: 12 May 2020 / Published online: 21 May 2020

(c) The Author(s), under exclusive licence to Springer Nature America, Inc. 2020

\begin{abstract}
There is limited information about newborns with confirmed or suspected COVID-19. Particularly in the hospital after delivery, clinicians have refined practices in order to prevent secondary infection. While guidance from international associations is continuously being updated, all facets of care of neonates born to women with confirmed or suspected COVID-19 are centerspecific, given local customs, building infrastructure constraints, and availability of protective equipment. Based on anecdotal reports from institutions in the epicenter of the COVID-19 pandemic close to our hospital, together with our limited experience, in anticipation of increasing numbers of exposed newborns, we have developed a triage algorithm at the Penn State Hospital at Milton S. Hershey Medical Center that may be useful for other centers anticipating a similar surge. We discuss several care practices that have changed in the COVID-19 era including the use of antenatal steroids, delayed cord clamping (DCC), mother-newborn separation, and breastfeeding. Moreover, this paper provides comprehensive guidance on the most suitable respiratory support for newborns during the COVID-19 pandemic. We also present detailed recommendations about the discharge process and beyond, including providing scales and home phototherapy to families, parental teaching via telehealth and in-person education at the doors of the hospital, and telehealth newborn follow-up.
\end{abstract}

$\checkmark$ Jeffrey R. Kaiser

jkaiser2@pennstatehealth.psu.edu

1 Division of Neonatal-Perinatal Medicine, Department of Pediatrics, Milton S. Hershey Medical Center, Hershey, PA, USA

2 Neonatal Intensive Care Unit, Department of Nursing, Milton S. Hershey Medical Center, Hershey, PA, USA

3 Department of Obstetrics and Gynecology, Milton S. Hershey Medical Center, Hershey, PA, USA

4 Division of Pediatric Hospital Medicine, Department of Pediatrics, Milton S. Hershey Medical Center, Hershey, PA, USA

5 Division of Pediatric Infectious Diseases, Department of Pediatrics, Milton S. Hershey Medical Center, Hershey, PA, USA

6 Division of Academic General Pediatrics, Department of Pediatrics, Milton S. Hershey Medical Center, Hershey, PA, USA

7 Division of Pediatric Critical Care Medicine, Department of Pediatrics, Milton S. Hershey Medical Center, Hershey, PA, USA

\section{Introduction}

SARS-CoV-2, a novel $\beta$-coronavirus, was first reported in December 2019 in Wuhan, China, as "pneumonia of unknown etiology" [1] prior to its isolation and identification by Chinese authorities in January 2020 [2, 3]. Coronavirus disease 2019 (COVID-19) is primarily a respiratory disease of varying severity [4], which presents more commonly as asymptomatic or mild disease in newborns when compared with adults [5-7]. SARS-CoV-2 is transmitted through respiratory droplets, infected fomites [8-10], and from airborne transmission during aerosolization procedures [11]. The American Academy of Pediatrics (AAP) published initial guidance on the management of neonates born to mothers with COVID-19 [12]. Another group recently published a practical resource for perinatalneonatal specialists, providing the most up-to-date information about COVID-19 during pregnancy [13]. Since the epidemiological data for this pandemic are rapidly evolving, neonatologists need to continuously update management 
strategies for neonates born to mothers with confirmed or suspected COVID-19 [13, 14].

\section{Transmission of SARS-CoV-2 to newborns}

Since the first reported case of neonatal COVID-19 in February 2020 [15], concerns about possible vertical transmission of SARS-CoV-2 have been raised [16-19]. Early Chinese reports suggested that vertical transmission of SARS-CoV-2 does not occur, as amniotic fluid, vaginal mucus, placenta, umbilical cord, cord blood, and neonatal stool specimens tested negative for the virus [20-27]. In addition, nasopharyngeal swabs from these newborns immediately after delivery were negative. Moreover, there were no reports of vertical transmission during the Severe Acute Respiratory Syndrome (SARS) and Middle East Respiratory Syndrome (MERS) outbreaks due to genetically similar coronaviruses [3, 28, 29].

Possible vertical transmission was raised by a case series describing three newborns with early-onset mild COVID-19 with positive results from reverse transcriptase-polymerase chain reaction (RT-PCR) tests performed on the second day after birth [16]. The authors argued that since strict infection prevention procedures were used during the deliveries, the early-onset infections resulted from vertical transmission. It is unclear, however, if strict isolation and infection control measures continued beyond the deliveries. The earliest reported neonatal positive test occurred in a $16 \mathrm{~h}$ old neonate born to a mechanically ventilated mother with COVID-19 after cesarean delivery with immediate isolation, at 33 weeks' gestation [30]. While the early positive test was concerning for a vertical infection, amniotic fluid, cord blood, and placenta were not tested for virus, and therefore secondary transmission could not be excluded [30].

In other case series, serological testing of seven newborns with limited postnatal exposure (mothers delivered by cesarean section wore masks and newborns were quickly separated from their mothers) demonstrated the presence of virusspecific antibodies, including three with high IgM levels, despite negative virology testing $[17,18]$. This may suggest transplacental passage of SARS-CoV-2 since IgM does not cross the placenta, although $\operatorname{IgM}$ assays are difficult to interpret due to frequent false positive results [19]. While postnatal transmission to newborns is most likely, current evidence is inconclusive regarding in utero transmission.

\section{Susceptibility of newborns and children to SARS-CoV-2}

Compared with adults, children are less susceptible to SARS-CoV-2 infection and experience less severe disease with significantly lower death rates [7, 31-34]. The physiological mechanisms underlying these differences are as yet unknown, but several possibilities exist that should be explored in future studies. The immature developing immune system of children may respond to SARS-CoV-2 differently than adults, possibly resulting in a less damaging cytokine reaction. SARS-CoV-2 binds to angiotensin converting enzyme-II (ACE-2) receptors on type II alveolar epithelial cells in the lower respiratory tract to gain entry into the lungs [35, 36], and ACE-2 receptors may be functionally immature in children making them less susceptible to SARS-CoV-2 infection [37].

\section{Fetal, neonatal, and infant characteristics}

Although the reasons are unclear, and causation cannot be implied, about half of mothers with COVID-19 delivered preterm infants [25]. Fetal growth during the third trimester does not appear to be affected in infected mothers [15, 22, 24, 25, 38]. Perinatal complications such as fetal distress and premature rupture of the membranes and postnatally, respiratory distress, tachycardia, shock, thrombocytopenia, and even death have been reported in some neonates (SARS-CoV-2 negative) born to mothers with COVID-19 [22, 24, 39]. Two stillbirths have been reported [40, 41], one from a pregnant woman who had acute respiratory distress syndrome and multi-organ failure leading to extracorporeal membrane oxygenation (ECMO), and another from a mother who eventually died [40, 41]. Maternal morbidity due to the disease may lead to morbidity and mortality in fetuses/newborns who test negative for SARS-CoV-2.

A few newborns who tested positive soon after birth had dyspnea, fever, pneumonia, respiratory distress syndrome, and feeding intolerance, with overall mild disease and no deaths [20, 30].

A large epidemiologic study from China of 2143 children with laboratory-confirmed or suspected COVID-19 reported that $17.7 \%$ of cases were in infants $<1$ year of age [31]. Another report from Wuhan Children's Hospital reported similar results [33]. A similar percentage (15.5\%) of pediatric cases in the United States occurred in infants < 1 year of age [34]. In China, a larger proportion of infants $<$ 1 year of age had severe/critical disease compared with older children (10.6\% vs $4.8 \%$ ) [31]. Similarly, in the United States, infants $<1$ year of age had the highest rates of hospitalization among pediatric patients [34].

\section{Delivery room management and resuscitation}

At Penn State, universal COVID-19 testing was implemented on April 10, 2020 for all patients admitted for 
delivery (Fig. 1). The unexpectedly high asymptomatic carrier rates reported from other institutions as well as prolonged face-to-face patient care required during labor and delivery drove this decision, allowing for judicious personal protective equipment (PPE) use and decreased potential exposure for both healthcare workers and newborns. When patients refuse testing, a protocol of contact and droplet isolation for both mother and newborn is used, and during the delivery, healthcare workers wear N95 respirators. Our obstetricians have cared for term COVID19 positive patients who delivered healthy newborns (viral testing negative), and one women who convalesced and was discharged, still pregnant, at 29 weeks' gestation.

Pregnant women with confirmed or suspected COVID-19 requiring hospitalization are admitted to negative-pressure rooms, preferentially with an adjoining patient room for newborn resuscitation. Mode of delivery is based on the progression of labor and routine obstetric indications. Operative vaginal deliveries are considered for women who require a shortened second stage of labor due to maternal exhaustion or respiratory distress.

At Penn State, cesarean deliveries occur in negativepressure operating rooms. The negative-pressure unit dedicated to COVID-19 positive pregnant patients is the surgical anesthesia intensive care unit (SAICU). Although in close proximity to the operating rooms, we learned during the labor of one patient that transporting patients with COVID19 present many logistical challenges (need for multiple cleanings of patient equipment and for Security to clear hallways) that would delay an emergency cesarean delivery. Although this patient ultimately delivered vaginally, this scenario raised many questions about lowering the threshold for cesarean delivery for patients with COVID-19 in the future. Moreover, transport of the newborn, considered a person under investigation (PUI) [42], out of the SAICU was also delayed by the institution's COVID-19 transport policy. This has since been remedied with updated policies that allow newborn PUIs to be transferred to their rooms in a transport isolette.

Due to frequent exposure to aerosolizing procedures during the second stage of labor, the possible use of general endotracheal anesthesia during emergency cesarean sections, and the possible need for neonatal intubation, labor, and delivery staff are at frequent risk of exposure [43]. Delivery providers and nurses wear full PPE ("full PPE" = isolation gown, N95 respirator or powered, air purifying respirator, face shield or goggles, and gloves) [44] during the entire labor and delivery process of mothers with confirmed or suspected COVID-19, and mothers wear surgical masks.

\section{Antenatal corticosteroids}

Data are limited on how corticosteroids affect pregnant patients with COVID-19. Steroids given to MERS and SARS patients offered no clinical benefit and prolonged

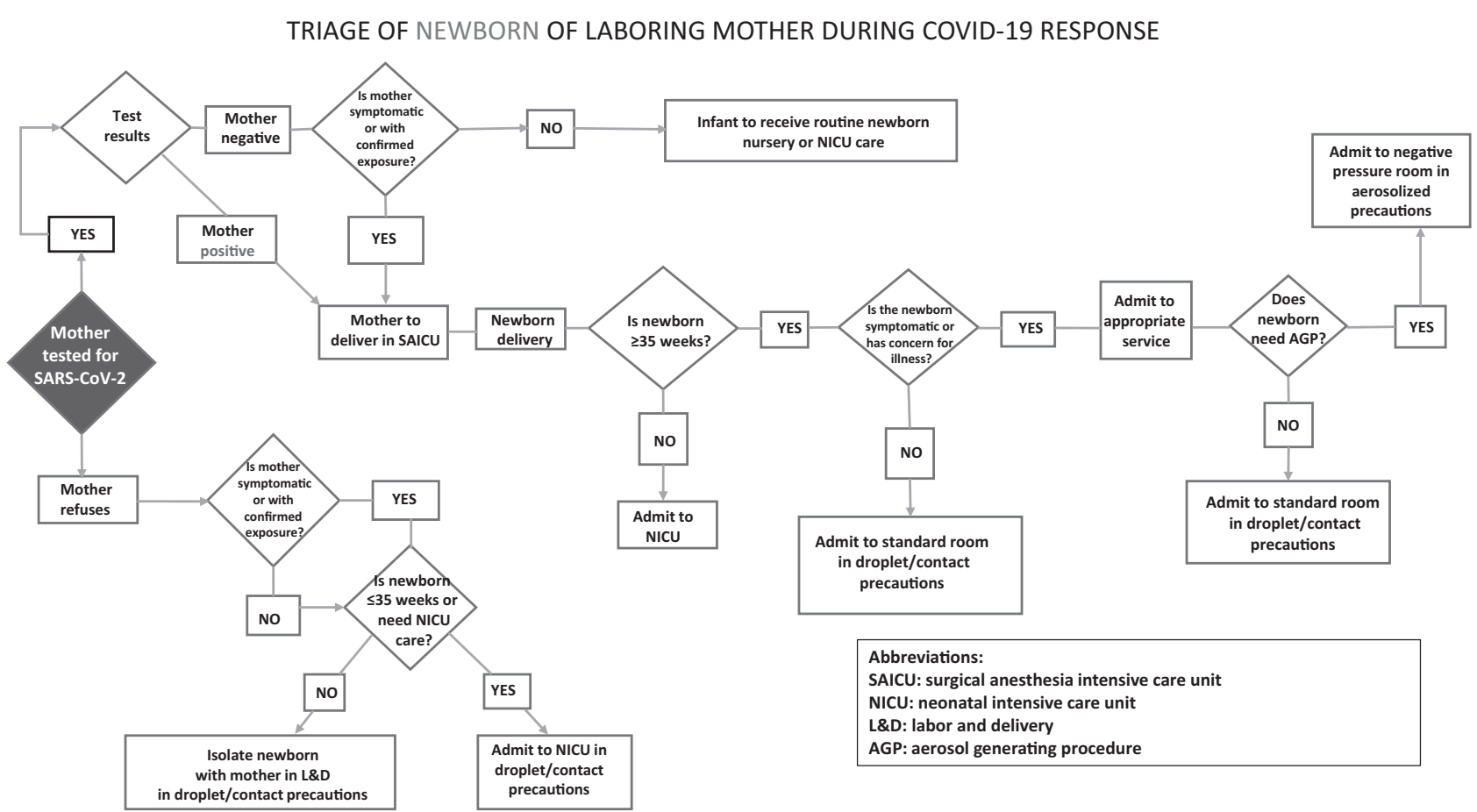

Fig. 1 Penn State algorithm for the triage of newborns of laboring mothers during COVID-19. The triage begins with the laboring mother undergoing testing for SARS-CoV-2 to determine delivery location and disposition of the newborn to the appropriate location and care service. 
viral shedding [45, 46]. The American College of Obstetricians and Gynecologists (ACOG) recommends the continued use of antenatal corticosteroids for asymptomatic women or those with mild COVID-19 who are at risk of preterm birth within the next 7 days at $<336 / 7$ weeks' gestation [43]. If the mother is ill [47], however, the risks to the mother and the potential benefits to the fetus must be weighed and discussed with the mother and family.

\section{Delayed cord clamping (DCC)}

The benefits of DCC for preterm and term neonates are well known [48]. Several reports, based on expert opinion, have recommended that DCC not be performed in neonates born to mothers with confirmed or suspected COVID-19 in order to reduce the risk of secondary transmission [15, 47, 49]. In contrast, the ACOG and the Royal College of Obstetricians and Gynecologists, based on a lack of evidence that brief exposure to the mother causes neonatal infection, still recommends performing DCC [43, 50]. Another group recommends performing DCC with the newborn held by the obstetrician [51].

At Penn State, we now perform DCC with the obstetrician holding spontaneously breathing newborns rather than placing them skin-to-skin on the mother.

\section{Newborn resuscitation and routine care}

At Penn State, a COVID-19 resuscitation team (neonatal delivery nurse, a respiratory therapist, and a neonatologist) is available for all deliveries of mothers with confirmed or suspected COVID-19. A pediatric infectious diseases consult is obtained on all neonates born to mothers with confirmed COVID-19 (or symptomatic mothers who initially test negative) so that appropriate testing and discharge follow-up is established.

\section{Newborns $\geq 35$ weeks' gestation}

For newborns not predicted to need extensive resuscitation, a neonatal delivery nurse (fully donned) enters the room immediately after delivery and evaluates gestational age, tone, color, and respiratory effort. If there is good tone with spontaneous breathing, the nurse wraps the newborn with warm blankets and places her/him into a prewarmed transport isolette.

Hospital staff caring for these newborns don a gown, surgical mask, face shield, and gloves. In order to minimize PPE use and potential exposures, routine newborn tests such as screening for congenital heart disease, obtaining the newborn screen, and hearing testing are performed together.

\section{Newborns $<35$ weeks' gestation}

For resuscitation of premature, high-risk, and newborns with anomalies born to mothers with cinfirmed or suspected COVID-19, a fully donned neonatal resuscitation team enters the room upon delivery. The newborn is quickly assessed, and if spontaneously breathing, is placed into the transport incubator. If resuscitation is required, necessary respiratory support is provided, and the newborn is transported to the neonatal intensive care unit (NICU) and admitted into a negative-pressure room with an antechamber. Mechanical ventilation, ECMO, and surgeries can be performed in this room. Care is provided by a neonatal nurse trained in donning and doffing PPE. A second nurse monitors donning and doffing to ensure that contamination of the primary nurse or medical provider does not occur. The minimum number of persons needed to provide care to these newborns are allowed to enter the room. Healthcare workers who are pregnant or $\geq 60$ years of age do not care for these patients [52].

At Penn State, the initial SARS-CoV-2 test is performed within $24-48 \mathrm{~h}$ after birth. For newborns who initially test positive and remain in the NICU for extended periods, additional testing occurs on a case-by-case basis, likely every $48 \mathrm{~h}$, and based on signs and severity of COVID-19.

\section{Mother and newborn separation and visitation}

The AAP, ACOG, and Chinese consensus experts recommend separating newborns from mothers with confirmed or suspected COVID-19 into separate isolation rooms until the mother's transmission-based precautions are discontinued $[12,15,43,49]$. The presumed benefits of temporary separation, i.e., decreased risk of neonatal infection, should be discussed with families prior to delivery $[12,42]$. The Centers for Disease Control (CDC) recently (April 4, 2020) changed their guidance regarding separating newborns from mothers with confirmed or suspected COVID-19 [42]. They now recommend that the decision to separate newborns should be made on a case-by-case basis, using shared decision-making between mothers and families and the healthcare team about the risks and benefits of cohabitating [42]. If rooming in does occur according to the families' wishes, or because of facility constraints, care should be taken to practice social distancing, hand hygiene, and infection control, and the mother should wear a facemask during contact with her newborn [42].

At Penn State, due to facility infrastructure constraints, mothers with confirmed or suspected COVID-19 and newborns are admitted to different hospital units; thus they are separated. While hospitalized, mothers with COVID-19 
remain in the hospital's COVID unit. Mothers who are discharged home prior to the infant's discharge may visit their newborns after they have been afebrile for 3 days, symptoms have abated or are improving, and $>7$ days have passed since their symptoms first began. Alternatively, they can visit if they have two negative tests ( $>24 \mathrm{~h}$ apart), are afebrile without antipyretics, and respiratory symptoms have improved [12, 42]. Other family support persons who are PUIs may not visit the baby until their own SARS-CoV2 molecular testing is negative and any symptoms have abated [12]. Visitors are instructed on proper techniques for donning and doffing masks, gowns, and gloves. Various technology platforms are used to video conference with families who are unable to visit.

In the NICU, newborns who tests negative for SARSCoV-2 and have no signs can be moved to a regular room [42].

\section{Breastfeeding and breast milk}

Breast milk has innumerable benefits for newborns, including passive transmission of antibodies against various infections [53]. Antibodies to a similar virus, SARS-CoV, were detected in breast milk [54]. To date, SARS-CoV-2 has not been detected in the breast milk of mothers with COVID-19 [22], and it is possible that breast milk from these mothers will provide some degree of immunity. Thus, most international associations highly recommend using breast milk from mothers with confirmed or suspected COVID-19 [42, 55-57].

Careful collection techniques should be used for pumped breast milk [42], including providing mothers with a dedicated breast pump. Mothers should wash their hands before and after pumping, and the breast pump should be properly disinfected per the manufacturer's instructions. If possible, expressed breast milk should be fed to newborns by a healthy caregiver. If a mother with confirmed or suspected COVID-19 chooses to directly breastfeed, she should wear a surgical mask and perform hand and breast hygiene prior to feeding. When the mother is not breastfeeding, the newborn should remain $>2 \mathrm{~m}$ ( $\sim 6 \mathrm{ft})$ away, be separated by a barrier, and/or be placed in an isolette. The World Health Organization and United Nations Children's Fund recommend standard breastfeeding guidelines within an hour of birth using appropriate infection prevention precautions $[55,56]$. This advice may be most pertinent to areas where limited resources make breastfeeding the only viable option.

Since SARS-CoV-2 has been detected on plastic for up to $72 \mathrm{~h}$ [58], staff receiving bottles of expressed milk from mothers with COVID-19 should wear gloves. After securing the cap, bottles should be wiped with viricidal wipes or diluted bleach solutions and placed on a clean surface to air dry. After drying, bottles may be placed in hospital refrigerators in individual patient bins [59].

For long-term NICU stays, donor human milk is an option if maternal breast milk is not available. Human Milk Banking Association of North America milk banks uniformly use heat treatment during Holder pasteurization [60], which totally inactivates genetically similar viruses (SARSCoV and MERS-CoV) [61, 62]. While there is currently no evidence regarding SARS-CoV-2, it is likely inactivated during heating.

At Penn State, during hospitalization, infected mothers are encouraged to provide expressed breast milk. Unfortunately, due to being in separate units, direct breastfeeding is not currently possible. At other institutions, where there is an opportunity for cohabitation, the decision to directly breastfeed can be made using shared decision-making between mothers and healthcare teams about the risks and benefits of direct breastfeeding.

\section{Airway management and respiratory support of newborns with confirmed or suspected COVID-19}

Aerosolization procedures increase the risk of airborne transmission, particularly to healthcare workers, since SARS-CoV-2 can remain in the air for $>3 \mathrm{~h}$ and travel $>2 \mathrm{~m}$ $(\sim 6 \mathrm{ft})[58,63]$. Droplet transmission occurs when larger respiratory droplets are generated by infected individuals through coughing, sneezing, and talking. These larger droplets drop quickly and only travel a short distance, usually

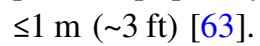

Fortunately, there are very few reports of respiratory support needs in neonates with confirmed or suspected COVID-19 [16, 64]. Most exposed neonates who received mechanical ventilation also had comorbidities such as prematurity, asphyxia, and non-COVID-19 sepsis [16].

\section{Protection of healthcare workers during respiratory care}

Guidance of respiratory care of patients with confirmed or suspected COVID-19 remain fluid [44, 65, 66]. Since up to $29 \%$ cases in Wuhan, China, occurred in healthcare workers [67], aerosolization properties and stability of SARS-CoV-2 in the environment cannot be overemphasized [58]. Therefore, common aerosolizing procedures in the NICU, such as intubation, extubation, open suctioning, noninvasive ventilation, and placement of naso- and oro-gastric tubes need to be conducted with a high degree of caution, using appropriate PPE in negative-pressure rooms [11, 44]. Institutional variation of what is considered an aerosol generating procedure and how that will affect professionals 
caring for COVID-19 patients adds another layer of complexity $[68,69]$. A single center study showed that the team members who directly performed these procedures were at highest risk of becoming infected [70]. Institutions should critically assess the literature in light of their specific patient population and resources in order to determine what they consider aerosol generating procedures.

\section{Noninvasive respiratory support}

Noninvasive support such as nasal intermittent positive pressure ventilation, nasal continuous positive airway pressure (CPAP), high flow nasal cannula, and nasal cannula oxygen therapy can be generated by several devices in the NICU. Since they are open systems at the patient interface, there is a large risk for droplet and airborne transmission [71]. Masks covering both the nose and mouth, as well as using the lowest possible pressure, may minimize some of the risk. Further, if noninvasive ventilation is generated by mechanical ventilators with high-efficiency particulate air (HEPA) filters, the risk of aerosolization is likely lower. Interestingly, during the SARS epidemic, nurses caring for patients receiving noninvasive ventilation did not contract more disease than those who cared for patients on ventilators [72].

\section{Invasive respiratory support}

Rapid sequence intubation is recommended for those in respiratory failure with COVID-19 [73]. If bag-mask ventilation is needed, providers should place a HEPA filter between the mask and the end tidal $\mathrm{CO}_{2}$ device and oxygen source [65, 74], and wear full PPE [44]. If PPE is likely to inhibit the ability to visualize the vocal cords, video laryngoscopy should be performed [66]. Pulmonary hygiene should be minimized [75]. Suctioning of endotracheal tubes should be performed using in-line suctioning catheters $[11,65]$. If a patient needs to be disconnected from the ventilator, the endotracheal tube should be clamped and the circuit disconnected with the heat moisture exchanger still attached to the patient $[11,65]$.

Conventional ventilators with dual limb circuits with expiratory HEPA filters connected to cuffed endotracheal tubes [76] are nearly closed systems that significantly decrease the risk of aerosolization. The high-frequency oscillator ventilator (HFOV, Sensormedics, Yorba Linda, CA), without specialized experimental circuits, is not able to filter the exhaled air, making its use especially worrisome to healthcare workers during a viral epidemic [77]. During the SARS outbreak, however, healthcare workers caring for patients on HFOV did not become infected more than those caring for patients receiving conventional ventilation [72]. The high-frequency jet ventilator (HFJV, Bunnell, Salt Lake
City, UT) has an expulsion set with a filter that prevents aerosol generation [77].

At Penn State, noninvasive ventilation (using a ventilator) for newborns with confirmed or suspected COVID-19 is the preferred mode. If mechanical ventilation is needed, conventional ventilation is failing, or high-frequency ventilation is desired, neonates are placed on the HFJV. Newborns $\geq$ $1500 \mathrm{~g}$ with confirmed or suspected COVID-19 are placed on ventilators with capabilities to do both invasive and noninvasive ventilation, Thus, respiratory care can be adjusted without contaminating multiple devices. In surge situations with inadequate number of ventilators, bubble or variable flow CPAP may be used.

\section{Laboratory and radiologic evaluation}

The diagnosis of COVID-19 in newborns includes physical examination, laboratory, and radiologic testing $[4,24,31]$.

\section{Laboratory evaluation}

A SARS-CoV-2 RT-PCR is done for asymptomatic PUIs [15]. For symptomatic PUIs and COVID-19 infected newborns, additional tests such as CBC and CRP should be performed, as well as other tests that are clinically indicated [15]. While the diagnostic role of serologic testing is currently unclear, it may be useful for future epidemiological purposes [78].

\section{Sample collection and virus identification}

The CDC recommends obtaining a nasopharyngeal swab (or a bronchoalveolar lavage sample if receiving invasive ventilation) for initial diagnostic testing [79]. RT-PCR is currently recommended for the qualitative detection of SARS-CoV-2 nucleic acid in respiratory tract specimens [80]. The Emergency Use Authorization FDA approved test used at Penn State is the Simplexa COVID-19 Direct Kit (DiaSorin Molecular, Cypress, CA). It has excellent specificity. For newborns, the AAP recommends obtaining throat and nasopharynx swabs at about 24 and $48 \mathrm{~h}$ after birth, although the optimal time of testing is unknown [12]. The testing regimen should also take into account the risk of infection and limitations of resources. Additional testing in symptomatic neonates should be considered because early test results may be negative due to the incubation period of the virus. A respiratory viral panel, to rule out other infections, should also be considered in symptomatic neonates [15].

\section{Radiologic evaluation}

Chest $\mathrm{x}$-ray findings are variable and nonspecific including unilateral or bilateral ground-glass opacity, lobar or 
subsegmental areas of lung consolidation, pneumothorax, and are sometimes normal [15, 16, 24, 81-83]. CT scans do not appear to provide additional diagnostic information $[4,16,23,84]$. Given the limited sensitivity, specificity, and radiation exposure, imaging should only be performed if clinically indicated.

\section{Discharge and outpatient follow-up}

\section{Healthy newborns $\geq 35$ weeks' gestation}

Routine newborn criteria, including stable physical exam, ability to maintain body temperature, and feeding well with adequate hydration, are used to establish timing of discharge. All families, courtesy of the Children's Miracle Network, are given a baby scale (Baby/Toddler Electronic Scale, model \#914, Salter). If serum bilirubin (which may be done concurrently with the newborn screen) is in the high intermediate or high-risk zone [85], they are also loaned home phototherapy (Bilibed ${ }^{\circ}$, model 1544976, Medela, Baar, Switzerland).

\section{Parental education}

Advice regarding home isolation precautions follow the AAP guidelines [12]. Neonates are ideally discharged into the care of an unaffected caregiver. COVID-19 positive family members are instructed to limit exposure to the newborn, generally maintaining a $2 \mathrm{~m}(\sim 6 \mathrm{ft})$ distance. If the mother is breastfeeding or provides newborn care, she is instructed on hand hygiene and use of a mask until afebrile for $72 \mathrm{~h}$ without the use of antipyretics, and $>7$ days have passed since symptoms began [12].

Predischarge education is completed using video conferencing during the mother's hospital stay or at home following maternal discharge. On the day of discharge, the neonate is brought to a less trafficked entrance of the hospital by the discharging nurse (with a scale and home phototherapy, if needed) and is met by the family (likely still being quarantined) who are wearing gloves and a mask, for a complete in-person teaching session. During this interaction, parents and staff maintain $2 \mathrm{~m}(\sim 6 \mathrm{ft})$ social distancing, and take turns moving in and out of the teaching space without exposing other staff or patients to the family and newborn. Lastly, parents are instructed on the use of the scale and phototherapy, about monitoring for signs of neonatal illness, and details about medical follow-up and additional testing.

\section{Medical follow-up}

Infants are followed up 1-2 days after discharge via telehealth. An informal poll of local primary care providers indicated that only $2 \%$ had a plan in place to care for these newborns as outpatients. The focus of the video visit is to evaluate for developing signs of infection, review home isolation precautions, and discuss routine concerns such as feeding, hydration, and jaundice. Neonates are weighed on the home scale during the encounter, allowing the pediatrician to visualize the neonate's tone, color, demeanor, and respiratory status. If the pediatrician is concerned about jaundice, or if the infant was discharged with home phototherapy, arrangements are made for a laboratory technician in full PPE to obtain a serum bilirubin sample in the home. Alternatively, a Chinese group developed an online bilirubin follow-up program for parents, with video education for using an online app to check transcutaneous bilirubin levels [86]. If the pediatrician is concerned that the neonate appears ill, the family is directed to the Emergency Department.

The timing of subsequent telehealth visits is determined by the initial visit and the neonate's prior history. At 14 days after birth, a repeat test for SARS-CoV-2 is performed, although this is not recommended by the AAP. This is done to identify neonates who may be at risk of infecting others. If the 14 day test result is negative, routine baby care is transitioned back to the community primary care provider.

If readmission for a neonate born to a mother with confirmed or suspected COVID-19 is necessary for any reason, the neonate will undergo testing for COVID-19, regardless of the timing of previous tests, to ensure proper use of isolation rooms and PPE.

\section{Conclusion}

This paper reports Penn State's current guidelines, based on the most up-to-date literature, about managing mothers and newborns with confirmed or suspected COVID-19. While COVID-19 generally has a mild course in newborns and children, the disease continues to evolve and has caused major morbidity and mortality worldwide. Although vertical transmission is unlikely, monitoring of neonates born to mothers with confirmed or suspected COVID-19 is imperative. While many facets of care remain the same, other practices such as antenatal corticosteroids, DCC, separation and visitation, breastfeeding, airway management and respiratory support, and neonatal follow-up have been impacted by COVID-19. While we hope our policies and procedures may be helpful to other institutions, each center must develop and revise their guidelines to provide optimal care for patients while conserving vital PPE and ventilators and protecting healthcare workers. Given the low rate of disease in newborns to date, our policies may change in the near future to allow cohabitation, direct 
breastfeeding, and routine newborn care for newborn PUIs without signs of disease.

Author contributions SA and JRK conceptualized, drafted, and revised the article, and gave final approval to its content. TEC, CKG, KMG, MJK, DJM, CNO-M, SJM, YLM, TWP, MS, AF, JA, DP, CRB, BMS, PJG, JEE, JRM, JMP, DCW, GDM, RSL, and SMI drafted and revised the article, and gave final approval for its content.

\section{Compliance with ethical standards}

Conflict of interest The authors declare that they have no conflict of interest.

Publisher's note Springer Nature remains neutral with regard to jurisdictional claims in published maps and institutional affiliations.

\section{References}

1. Hui DS, Azhar EI, Madani TA, Ntoumi F, Kock R, Dar O, et al. The continuing 2019-nCoV epidemic threat of novel coronaviruses to global health: the latest 2019 novel coronavirus outbreak in Wuhan, China. Int J Infect Dis. 2020;91:264-6.

2. World Health Organization. Novel coronavirus-China. World Health Organization; 2020. https://www.who.int/csr/don/12-janua ry-2020-novel-coronavirus-china/en/.

3. Lu R, Zhao X, Li J, Niu P, Yang B, Wu H, et al. Genomic characterisation and epidemiology of 2019 novel coronavirus: implications for virus origins and receptor binding. Lancet. 2020; 395:565-74.

4. Zhu N, Zhang D, Wang W, Li X, Yang B, Song J, et al. A novel coronavirus from patients with pneumonia in China, 2019. N Eng J Med. 2020;382:727-33.

5. Wei M, Yuan J, Liu Y, Fu T, Yu X, Zhang Z-J. Novel coronavirus infection in hospitalized infants under 1 year of age in China. JAMA. 2020. https://doi.org/10.1001/jama.2020.2131.

6. Brodin P. Why is COVID-19 so mild in children? Acta Paediatr. 2020. https://doi.org/10.1111/apa.15271.

7. Ludvigsson JF. Systematic review of COVID-19 in children show milder cases and a better prognosis than adults. Acta Paediatr. 2020. https://doi.org/10.1111/apa.15270.

8. Li Q, Guan X, Wu P, Wang X, Zhou L, Tong Y, et al. Early transmission dynamics in Wuhan, China, of novel coronavirusinfected pneumonia. N Eng J Med. 2020;382:1199-207.

9. Hong H, Wang Y, Chung HT.Chen CJ, Clinical characteristics of novel coronavirus disease 2019 (COVID-19) in newborns, infants and children. Pediatr Neonatol. 2020;S1875-9572:30026-7. https://doi.org/10.1016/j.pedneo.2020.03.001.

10. Shen K, Yang Y, Wang T, Zhao D, Jiang Y, Jin R, et al. Diagnosis, treatment, and prevention of 2019 novel coronavirus infection in children: experts' consensus statement. World J Pediatr. 2020. https://doi.org/10.1007/s12519-020-00343-7.

11. World Health Organization. Clinical management of severe acute respiratory infection (SARI) when COVID-19 disease is suspected. Interim guidance (13 March 2020). World Health Organization; 2020. https://www.who.int/publications-detail/clinicalmanagement-of-severe-acute-respiratory-infection-when-novelcoronavirus-(ncov)-infection-is-suspected.

12. Puopolo KM, Hudak ML, Kimberlin DW, Cummings J, American Academy of Pediatrics Committee on Fetus and Newborn Section of Neonatal Perinatal Medicine and Committee on Infectious Disease. Initial guidance: management of infants born to mothers with COVID-19. 2020. https://downloads.aap.org/AAP/PDF/ COVID\%2019\%20Initial\%20Newborn\%20Guidance.pdf.

13. Mimouni F, Lakshminrusimha S, Pearlman SA, Raju T, Gallagher PG, Mendlovic J. Perinatal aspects on the covid-19 pandemic: a practical resource for perinatal-neonatal specialists. J Perinatol. 2020. https://doi.org/10.1038/s41372-020-0665-6.

14. Lu Q, Shi Y. Coronavirus disease (COVID-19) and neonate: what neonatologist need to know. J Med Virol. 2020. https://doi.org/10. 1002/jmv.25740.

15. Wang L, Shi Y, Xiao T, Fu J, Feng X, Mu D, et al. Chinese expert consensus on the perinatal and neonatal management for the prevention and control of the 2019 novel coronavirus infection (First edition). Ann Transl Med. 2020;8:47.

16. Zeng L, Xia S, Yuan W, Yan K, Xiao F, Shao J, et al. Neonatal early-onset infection with SARS-CoV-2 in 33 neonates born to mothers with COVID-19 in Wuhan, China. JAMA Pediatr. 2020. https://doi.org/10.1001/jamapediatrics.2020.0878.

17. Zeng H, Xu C, Fan J, Tang Y, Deng Q, Zhang W, et al. Antibodies in infants born to mothers with COVID-19 pneumonia. JAMA. 2020. https://doi.org/10.1093/infdis/jiaa113.

18. Dong L, Tian J, He S, Zhu C, Wang J, Liu C, et al. Possible vertical transmission of SARS-CoV-2 from an infected mother to her newborn. JAMA. 2020. https://doi.org/10.1001/jama.2020.4621.

19. Kimberlin DW, Stagno S. Can SARS-CoV-2 infection be acquired in utero? More definitive evidence is needed. JAMA. 2020. https://doi.org/10.1001/jama.2020.4868.

20. Schwartz DA. An analysis of 38 pregnant women with COVID19, their newborn infants, and maternal-fetal transmission of SARS-CoV-2: maternal coronavirus infections and pregnancy outcomes. Arch Pathol Lab Med. 2020. https://doi.org/10.1007/ s12630-020-01630-7.

21. Schwartz DA, Graham AL. Potential maternal and infant outcomes from coronavirus 2019-nCoV (SARS-CoV-2) infecting pregnant women: Lessons from SARS, MERS, and other human coronavirus infections. Viruses. 2020;12:194. https://doi.org/10. 3390/v12020194.

22. Chen H, Guo J, Wang C, Luo F, Yu X, Zhang W, et al. Clinical characteristics and intrauterine vertical transmission potential of COVID-19 infection in nine pregnant women: a retrospective review of medical records. Lancet. 2020;395:809-15.

23. Liu W, Wang Q, Zhang Q, Chen L, Chen J, Zhang B, et al. Coronavirus disease 2019 (COVID-19) during pregnancy: a case series. Preprints. 2020;2020020373.

24. Zhu H, Wang L, Fang C, Peng S, Zhang L, Chang G, et al. Clinical analysis of 10 neonates born to mothers with 2019-nCoV pneumonia. Transl Pediatr. 2020;9:51-60.

25. Mullins E, Evans D, Viner RM, O’Brien P, Morris E. Coronavirus in pregnancy and delivery: rapid review. Ultrasound Obstet Gynecol. 2020. https://doi.org/10.1002/uog.22014.

26. Wang S, Guo L, Chen L, Liu W, Cao Y, Zhang J, et al. A case report of neonatal COVID-19 infection in China. Clin Infect Dis. 2020. https://doi.org/10.1093/cid/ciaa225.

27. Fan C, Lei D, Fang C, Li C, Wang M, Liu Y, et al. Perinatal transmission of COVID-19 associated SARS-CoV-2: should we worry? Clin Infect Dis. 2020. https://doi.org/10.1093/cid/ciaa226.

28. Ng PC, Leung CW, Chiu WK, Wong SF, Hon EK. SARS in newborns and children. Biol Neonate. 2004;85:293-8.

29. Alserehi H, Wali G, Alshukairi A, Alraddadi B. Impact of Middle East Respiratory Syndrome coronavirus (MERS-CoV) on pregnancy and perinatal outcome. BMC Infect Dis. 2016;16:105.

30. Alzamora MC, Paredes T, Caceres D, Webb CM, Valdez LM, La Rosa M. Severe COVID-19 during pregnancy and possible vertical transmission. Am J Perinatol. 2020. https://doi.org/10.1055/s0040-1710050.

31. Dong Y, Mo X, Hu Y, Qi X, Jiang F, Jiang Z, et al. Epidemiological characteristics of 2143 pediatric patients with 2019 
coronavirus disease in China. Pediatrics. 2020;e20200702. https:// doi.org/10.1542/peds.2020-0702.

32. Guan W-J, Ni Z-Y, Hu Y, Liang W-H, Ou C-Q, He J-X, et al. Clinical characteristics of coronavirus disease 2019 in China. $\mathrm{N}$ Eng J Med. 2020. https://doi.org/10.1056/NEJMoa2002032.

33. Lu X, Zhang L, Du H, Zhang J, Li YY, Qu J, et al. SARS-CoV-2 infection in children. N Engl J Med. 2020. https://doi.org/10.1056/ NEJMc2005073.

34. Team CC-R. Coronavirus disease 2019 in children-Unites States, February 12-April 2, 2020. MMWR Morb Mortal Wkly Rep. 2020. https://doi.org/10.15585/mmwr.mm6914e4.

35. Hoffmann M, Kleine-Weber H, Schroeder S, Kruger N, Herrler T, Erichsen S, et al. SARS-CoV-2 cell entry depends on ACE2 and TMPRSS2 and is blocked by a clinically proven protease inhibitor. Cell 2020;S0092-8674:30229-4. https://doi.org/10.1016/j. cell.2020.02.052.

36. Zhou P, Yang XL, Wang XG, Hu B, Zhang L, Zhang W, et al. A pneumonia outbreak associated with a new coronavirus of probable bat origin. Nature. 2020;579:270-3.

37. Diaz JH. Hypothesis: angiotensin-converting enzyme inhibitors and angiotensin receptor blockers may increase the risk of severe COVID-19. J Travel Med. 2020. https://doi.org/10.1093/jtm/taaa041.

38. Liu H, Liu F, Li J, Zhang T, Wang D, Lan W. Clinical and CT imaging features of the COVID-19 pneumonia: focus on pregnant women and children. J Infect. 2020;S0163-4453:30118-3. https:// doi.org/10.1016/j.jinf.2020.03.007.

39. Liu D, Li L, Wu X, Zheng D, Wang J, Yang L, et al. Pregnancy and perinatal outcomes of women with coronavirus disease (COVID-19) pneumonia: a preliminary analysis. AJR. 2020;1-6. https://doi.org/10.2214/AJR.20.23072.

40. Liu Y, Chen H, Tang K, Guo Y. Clinical manifestations and outcome of SARS-CoV-2 infection during pregnancy. J Infect. 2020; S0163-4453:30109-2. https://doi.org/10.1016/j.jinf.2020.02.028.

41. Karami P, Naghavi M, Feyzi A, Aghamohammadi M, Novin MS, Mobaien A, et al. Mortality of a pregnant patient diagnosed with COVID-19: a case report with clinical, radiological, and histopathological findings. Travel Med Infect Dis. 2020. https://doi. org/10.1016/j.tmaid.2020.101665.

42. Centers for Disease Control. Interim considerations for infection prevention and control of coronavirus disease 2019 (COVID-19) in inpatient obstetric healthcare settings. Centers for Disease Control; 2020. https://www.cdc.gov/coronavirus/2019-ncov/hcp/ inpatient-obstetric-healthcare-guidance.html.

43. American College of Obstetricians and Gynecologists. Practice advisory: novel coronavirus 2019 (COVID-19). 2020. https://www. acog.org/clinical/clinical-guidance/practice-advisory/articles/2020/ 03/novel-coronavirus-2019.

44. Centers for Disease Control. Using PPE. Centers for Disease Control; 2020. https://www.cdc.gov/coronavirus/2019-ncov/hcp/ using-ppe.html.

45. Arabi YM, Mandourah Y, Al-Hameed F, Sindi AA, Almekhlafi GA, Hussein MA, et al. Corticosteroid therapy for critically ill patients with Middle East Respiratory Syndrome. Am J Respir Crit Care Med. 2018;197:757-67.

46. Lee N, Allen Chan KC, Hui DS, Ng EK, Wu A, Chiu RW, et al. Effects of early corticosteroid treatment on plasma SARS-associated coronavirus RNA concentrations in adult patients. J Clin Virol. 2004:31:304-9.

47. Poon LC, Yang H, Lee JCS, Copel JA, Leung TY, Zhang Y, et al. ISUOG interim guidance on 2019 novel coronavirus infection during pregnancy and puerperium: information for healthcare professionals. Ultrasound Obstet Gynecol. 2020. https://doi.org/ 10.1002/uog. 22013.

48. Kresch MJ. Management of the third stage of labor: how delayed umbilical cord clamping can affect neonatal outcome. Am J Perinatol. 2017;34:1375-81.
49. Chen D, Yang H, Cao Y, Cheng W, Duan T, Fan C, et al. Expert consensus for managing pregnant women and neonates born to mothers with suspected or confirmed novel coronavirus (COVID19) infection. Int J Gynaecol Obstet. 2020. https://doi.org/10. 1002/ijgo.13146.

50. Royal College of Obstetricians and Gynaecologists. Coronavirus (COVID-19) infection in pregnancy: information for healthcare professionals. Royal College of Obstetricians and Gynaecologists; 2020. https://www.rcog.org.uk/globalassets/documents/guidelines/ 2020-04-03-coronavirus-covid-19-infection-in-pregnancy.pdf.

51. Chandrasekharan $P$, Vento $M$, Trevisanuto $D$, Partridge $E$, Underwood MA, Wiedeman J, et al. Neonatal resuscitation and postresuscitation care of infants born to mothers with suspected or confirmed SARS-CoV-2 infection. Am J Perinatol. 2020. https:// doi.org/10.1055/s-0040-1709688.

52. Buerhaus PI, Auerbach DI, Staiger DO. Older clinicians and the surge in novel coronavirus disease 2019 (COVID-19). JAMA. 2020. https://doi.org/10.1001/jama.2020.4978.

53. Hanson LA. Breastfeeding provides passive and likely longlasting active immunity. Ann Allergy Asthma Immunol. 1998;81:523-33. quiz 33-4, 37.

54. Robertson CA, Lowther SA, Birch T, Tan C, Sorhage F, Stockman L, et al. SARS and pregnancy: a case report. Emerg Infect Dis. 2004; 10:345-8.

55. World Health Organization. Breastfeeding advice during the COVID-19 outbreak. World Health Organization; 2020. http://www.emro.who.int/nutrition/nutrition-infocus/breastfeeding-a dvice-during-covid-19-outbreak.html.

56. UNICEF. Coronavirus disease (COVID-19): what parents should know. UNICEF; 2020. https://www.unicef.org/stories/novelcoronavirus-outbreak-what-parents-should-know.

57. Davanzo R, Moro G, Sandri F, Agosti M, Moretti C, Mosca F. Breastfeeding and coronavirus disease-2019. Ad interim indications of the Italian Society of Neonatology endorsed by the Union of European Neonatal \& Perinatal Societies. Matern Child Nutr. 2020. https://doi.org/10.1111/mcn.13010.

58. van Doremalen N, Bushmaker T, Morris DH, Holbrook MG, Gamble A, Williamson BN, et al. Aerosol and surface stability of SARS-CoV-2 as compared with SARS-CoV-1. N Engl J Med. 2020. https://doi.org/10.1056/NEJMc2004973.

59. Marinelli KA, Lawrence RM. Safe handling of containers of expressed human milk in all settings during the SARS-CoV-2 (COVID-19) pandemic. J Hum Lact. 2020. https://doi.org/10. 1177/0890334420919083.

60. Human Milk Banking Association of North America. Milk banking and COVID-19. Human Milk Banking Association of North America; 2020. https://www.hmbana.org/file_download/ inline/a04ca2a1-b32a-4c2e-9375-44b37270cfbd.

61. Darnell ME, Taylor DR. Evaluation of inactivation methods for severe acute respiratory syndrome coronavirus in noncellular blood products. Transfusion. 2006;46:1770-7.

62. van Doremalen N, Bushmaker T, Karesh WB, Munster VJ. Stability of Middle East respiratory syndrome coronavirus in milk. Emerg Infect Dis. 2014;20:1263-4.

63. Cook TM. Personal protective equipment during the COVID-19 pandemic - a narrative review. Anaesthesia. 2020. https://doi.org/ 10.1111/anae.15071.

64. Yu N, Li W, Kang Q, Xiong Z, Wang S, Lin X, et al. Clinical features and obstetric and neonatal outcomes of pregnant patients with COVID-19 in Wuhan, China: a retrospective, single-centre, descriptive study. Lancet Infect Dis. 2020;S1473-3099:30176-6. https://doi.org/10.1016/S1473-3099(20)30176-6.

65. Cook TM, El-Boghdadly K, McGuire B, McNarry AF, Patel A, Higgs A. Consensus guidelines for managing the airway in patients with COVID-19: guidelines from the Difficult Airway Society, the Association of Anaesthetists the Intensive Care 
Society, the Faculty of Intensive Care Medicine and the Royal College of Anaesthetists. Anaesthesia. 2020. https://doi.org/10. 1111/anae.15054.

66. Brewster DJ, Chrimes NC, Do TBT, Fraser K, Groombridge CJ, Higgs A, et al. Consensus statement: Safe Airway Society principles of airway management and tracheal intubation specific to the COVID-19 adult patient group. Med J Aust. 2020. https://www.mja.com.au/journal/2020/consensus-statement-safe-a irway-society-principles-airway-management-and-tracheal.

67. Koh D. Occupational risks for COVID-19 infection. Occup Med. 2020;70:3-5.

68. Tran K, Cimon K, Severn M, Pessoa-Silva CL, Conly J. Aerosol generating procedures and risk of transmission of acute respiratory infections to healthcare workers: a systematic review. PLOS ONE. 2012;7:e35797.

69. Davies A, Thomson G, Walker J, Bennett A. A review of the risks and disease transmission associated with aerosol generating medical procedures. J Infect Prev. 2009;10:122-6.

70. Macintyre CR, Seale H, Yang P, Zhang Y, Shi W, Almatroudi A, et al. Quantifying the risk of respiratory infection in healthcare workers performing high-risk procedures. Epidemiol Infect. 2014; 142:1802-8.

71. Simonds AK, Hanak A, Chatwin M, Morrell M, Hall A, Parker $\mathrm{KH}$, et al. Evaluation of droplet dispersion during non-invasive ventilation, oxygen therapy, nebuliser treatment and chest physiotherapy in clinical practice: implications for management of pandemic influenza and other airborne infections. Health Technol Assess. 2010;14:131-72.

72. Fowler RA, Guest CB, Lapinsky SE, Sibbald WJ, Louie M, Tang $\mathrm{P}$, et al. Transmission of severe acute respiratory syndrome during intubation and mechanical ventilation. Am J Respir Crit Care Med. 2004;169:1198-202.

73. Chavez S, Long B, Koyfman A, Liang SY. Coronavirus disease (COVID-19): a primer for emergency physicians. Am J Emerg Med. 2020. https://doi.org/10.1016/j.ajem.2020.03.036.

74. Kovacs G, Sowers N, Campbell S, French J, Atkinson P. Just the facts: airway management during the COVID-19 pandemic. CJEM. 2020;1-7. https://doi.org/10.1017/cem.2020.353.

75. Jing G, Li J. Expert consensus on preventing nosocomial transmission during respiratory care for critically ill patients infected by 2019 novel coronavirus pneumonia. Zhonghua jie he he hu xi za zhi. 2020;17:E020. https://doi.org/10.3760/cma.j.issn.10010939.2020.0020.

76. Edelson DP, Sasson C, Chan PS, Atkins DL, Aziz K, Becker LB, et al. Interim guidance for basic and advanced life support in adults, children, and neonates with suspected or confirmed COVID-19: from the Emergency Cardiovascular Care Committee and Get With the Guidelines $\left({ }^{\circledR}\right)$-Resuscitation Adult and Pediatric Task Forces of the American Heart Association in Collaboration with the American Academy of Pediatrics, American Association for Respiratory Care, American College of Emergency Physicians, The Society of Critical Care Anesthesiologists, and American Society of Anesthesiologists: supporting organizations: American Association of Critical Care Nurses and National EMS Physicians. Circulation. 2020. https://doi.org/10.1161/CIRCULATIONAHA. 120.047463.

77. Donic V, Torok P, Tomori Z. Preventing spread of aerosol infection during HFJV (including HFJV-M). In: Esquinos AM, editor. Noninvasive ventilation in high-risk infections and mass casualty events. Wein: Springer; 2014.

78. Zimmermann P, Curtis N. Coronavirus infections in children including COVID-19: an overview of the epidemiology, clinical features, diagnosis, treatment and prevention options in children. Pediatr Infect Dis J. 2020;39:355-68.

79. Centers for Disease Control. Evaluating and testing persons for cornoavirus disease 2019 (COVID-2019). Centers for Disease Control; 2020. https://www.cdc.gov/coronavirus/2019-nCoV/hcp/ clinical-criteria.html.

80. World Health Organization. Laboratory testing for coronavirus disease (COVID-19) in suspected human cases: Interim guidance (19 March 2020). World Health Organization; 2020. https://www. who.int/publications-detail/laboratory-testing-for-2019-novelcoronavirus-in-suspected-human-cases-20200117.

81. Huang C, Wang Y, Li X, Ren L, Zhao J, Hu Y, et al. Clinical features of patients infected with 2019 novel coronavirus in Wuhan, China. Lancet. 2020;395:497-506.

82. Wang J, Qi H, Bao L, Li F, Shi Y. A contingency plan for the management of the 2019 novel coronavirus outbreak in neonatal intensive care units. Lancet Child Adolesc Health. 2020;4:258-9.

83. Cruz A, Zeichner S. COVID-19 in children: initial characterization of the pediatric disease. Pediatrics. 2020;e20200834. https://doi.org/10.1542/peds.2020-0834.

84. Cui Y, Tian M, Huang D, Wang X, Huang Y, Fan L, et al. A 55day-old female infant infected with COVID 19: presenting with pneumonia, liver injury, and heart damage. J Infect Dis. 2020. https://doi.org/10.1093/infdis/jiaa113.

85. Bhutani VK, Johnson L, Sivieri EM. Predictive ability of a predischarge hour-specific serum bilirubin for subsequent significant hyperbilirubinemia in healthy term and near-term newborns. Pediatrics. 1999;103:6-14.

86. Ma XL, Chen Z, Zhu JJ, Shen XX, Wu MY, Shi LP, et al. Management strategies of neonatal jaundice during the coronavirus disease 2019 outbreak. World J Pediatr. 2020. https://doi. org/10.1007/s12519-020-00347-3. 